\title{
The need for invasive cardiological assessment and operation: viewpoint of a district general hospital
}

\author{
T CRIPPS, * M S DENNIS, † M JOY \\ From St Peter's Hospital, Chertsey, Surrey
}

SUMMARY The uptake of cardiac catheterisation and operation and of permanent pacemaker implantation in a district hospital in Surrey from 1979 to 1984 was studied prospectively. The 1982-84 figures for coronary artery operation indicated that 362 procedures/million population/annum were needed in the district. If patients with $\geqslant$ New York Heart Association grade II angina only received operation the corresponding figure would have been 325 . The national need for these procedures (464/million population/year) was estimated by correcting for the low standardised mortality ratio for ischaemic heart disease in the health district that was studied. Valvular heart disease accounted for 79 operations/million population/annum and permanent pacemaker insertion for 87 procedures/million population/annum. These figures underline the substantial shortfall in modern cardiac care in the United Kingdom.

The past two decades have seen substantial advances in both the techniques available to the cardiologist and in the scope of cardiac surgery. Information on the provision of cardiac surgery in the United Kingdom, ${ }^{1}$ the United States, ${ }^{23}$ West Germany, ${ }^{4}$ and Australias $^{5}$ suggests that the United Kingdom is behind other industrialised nations in the provision of cardiological care. An estimate of the requirement for cardiological investigation and operation is needed to plan for health care resource allocation. There are, however, no data currently available in the United Kingdom to indicate the likely demand for these procedures as district hospital facilities become more fully developed. We report on a prospective six year study of the uptake of invasive investigative facilities and operation by a district hospital cardiac unit that was set up in line with the recommendations of the Joint Cardiology Committee. ${ }^{6}$ The national need for these procedures was estimated by extrapolation after making some adjustment for regional variation in the prevalence of coronary artery disease.

Requests for reprints to Dr M Joy, St Peter's Hospital, Guildford Road, Chertsey, Surrey KT16 OPZ.

^Present address: St George's Hospital, London SW17. †Present address: St Thomas' Hospital, London SE1.

Accepted for publication 6 January 1986

\section{Patients and methods}

THE HEALTH DISTRICT

St Peter's Hospital, Chertsey, is the district hospital serving the North West Surrey Health District. The average population of the district during the period of the study (1979-84 inclusive) was 202000 . The proportion of those over retirement age was $17 \%$. The figure for England and Wales as a whole is $18 \%{ }^{7}$ The social class distribution of the population was skewed towards classes I and II. The standardised mortality ratio (SMR) for ischaemic heart disease (International Classification of Diseases 410-414) for the district was 0.78 and for valvar heart disease (International Classification of Diseases $393-398)$ it was $1 \cdot 00 .^{8}$

THE LOCAL CARDIAC DEPARTMENT

The establishment of the non-invasive cardiac department at St Peter's Hospital has been reported elsewhere. ${ }^{9}$ Facilities include computer assisted exercise electrocardiography, Holter monitoring, cross sectional echocardiography, and nuclear cardiology. There are four technicians. General practitioners are encouraged to refer all cardiological patients to the district hospital and more than $\mathbf{4 0 0 0}$ outpatient appointments are made each year. Patients with unstable angina and recent myocardial infarction are admitted to the four bedded coronary 
care unit which has approximately 550 admissions per annum. All patients within the hospital who require invasive cardiac assessment or operation are referred via the local department. Subsequent follow up is also performed locally.

\section{DIAGNOSTIC CATEGORIES}

Since 1979 a register has been kept of all patients referred from the district hospital for cardiac catheterisation and operation. Information is thus available on age, symptom and risk factor status, medication, and the outcome of invasive investigation and operation. The term ischaemic heart disease in this paper includes chronic stable angina, unstable angina, myocardial infarction, and atypical chest pain requiring angiography to assist in diagnosis. Also included in this group are those patients with heart failure secondary to coronary artery disease and non-rheumatic mitral regurgitation associated with coronary artery disease. The term valvar heart disease includes aortic valve disease with and without coronary artery disease, chronic rheumatic heart disease, and valve operation after bacterial endocarditis. Conditions falling outside these definitions are grouped together as "other".

\section{SYMPTOMS AND TREATMENT}

Symptoms were classified according to the New York Heart Association criteria. ${ }^{10}$ Antianginal medication and its dosage were recorded and contraindications and side effects were noted. Treatment with two or more agents was considered to be an adequate trial of medical treatment. ${ }^{11}$ Only data from the years 1982-84 were used to calculate the need for invasive investigation and coronary artery operation. This was when antianginal therapeutic regimens including $\beta$ blocking agents, calcium antagonists, and mononitrates became generally accepted and the early evidence of the long term benefits of operation were recognised. ${ }^{12}$

\section{INVASIVE DATA}

Analysis of the left ventriculograms and coronary angiograms was based on the reports of the investigating cardiologists. The severity, number, and site of stenoses were noted on a graticule and the disease was classified as single, two vessel, two vessel with proximal left anterior descending stenosis, three vessel, or left main stem stenosis, according to the European Trial Criteria ( $\geqslant 50 \%$ stenosis). ${ }^{12}$ The presence or absence of left ventricular impairment at angiography was also noted.

REVIEW OF CATCHMENT

To take account of the fact that some patients were

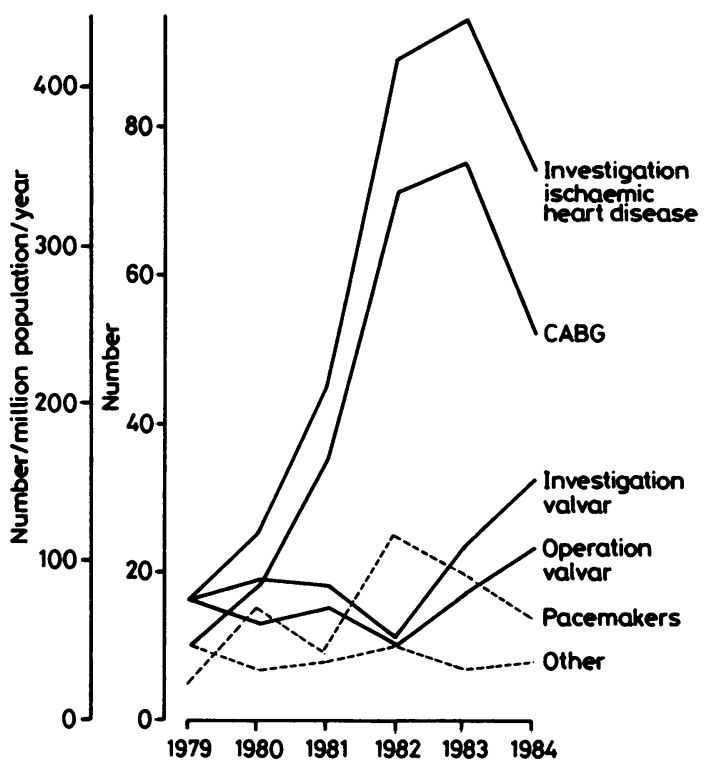

Fig. 1 The total number of patients referred from the district cardiac unit 1979-84 for invasive investigation, operation, and pacemaker implantation. The inner scale of the ordinate represents the number of patients and the outer scale the number of patients per million population.

referred directly to a cardiac centre (usually the National Heart or Brompton Hospitals) by their general practitioners we sent a postal questionnaire to the 109 principals in general practice in the district. Those who did not reply were telephoned. Only two declined to cooperate. In 1983 the South West Thames Regional Authority reviewed the origin of all patients undergoing investigation and/or operation in the National Heart and Brompton Hospitals. ${ }^{13}$ Thus there were accurate data on the number of patients living in the North West Surrey District who had coronary artery or valve operation in 1983 in these hospitals. These figures were assumed to be constant throughout the study period. We corrected for patients living outside the catchment area by excluding those who had home addresses outside the geographical catchment area at the time of referral.

\section{Results}

Figure 1 shows the total number of patients referred from the district cardiac unit for invasive investigation and operation during 1979-84. These figures do not include corrections for cross boundary inflow or outflow. The number of patients referred and operated upon for ischaemic heart disease 
increased until 1983 and declined in 1984. Ten patients (six in 1983 and four in 1984) who underwent percutaneous transluminal angioplasty are included in these figures, which also include three re-operations. Five of the ten angioplasty patients came to coronary artery bypass within six months. There has been a slower increase in the rate of investigation and operation for valvar heart disease and for permanent pacemaker insertion. Miscellaneous procedures such as pulmonary embolectomy remain infrequent.

\section{ISCHAEMIC HEART DISEASE}

The mean age of patients referred for coronary artery bypass operations increased from a mean (SEM) of $52(1.5)$ years to $55(1.0)$ years during the study period. The ratio of males to females varied but was approximately 6:1 overall. Despite the local policy not to refer smokers, $21 \%$ of patients said that they were smokers at presentation to the regional centre in 1979. This figure had fallen to $14 \%$ by 1984.

Forty seven per cent of all patients referred had New York Heart Association grade II or III angina and $25 \%$ had grade IV angina. Symptoms were less severe or absent in the remainder. Previous myocardial infarction had been documented in $46 \%$ of patients at the time of referral and $65 \%$ were found to have impaired left ventricular function at subsequent ventriculography. The waiting times for coronary angiography showed no consistent trend during the period. The mean waiting list time for angiography was 62 days and for operation it was 132 days. These not unfavourable waiting times, however, conceal very substantially longer periods, sometimes exceeding 18 months, for some patients. Urgent cases were usually accommodated. Three patients died on the waiting list for angiography. One had atypical pain and severe coronary artery disease at necropsy, one had New York Heart Association grade II, and one had grade III angina. Waiting time at death was one to four months. Four patients died on the waiting list for operation during the six year period. All had severe two or three vessel disease and had been waiting 1-20 months. There were two deaths within 24 hours of angiography (intractable ventricular fibrillation, myocardial infarction).

Figure 2 shows the distribution of coronary artery disease in the patients investigated. Figure 3 shows the angiographic findings in relation to symptoms and treatment. Several patients had angiographically severe lesions despite mild symptoms. The percentage of patients invasively investigated who proceeded to operation increased during the study period from $62 \%$ in 1979 to $80 \%$ in 1983 and

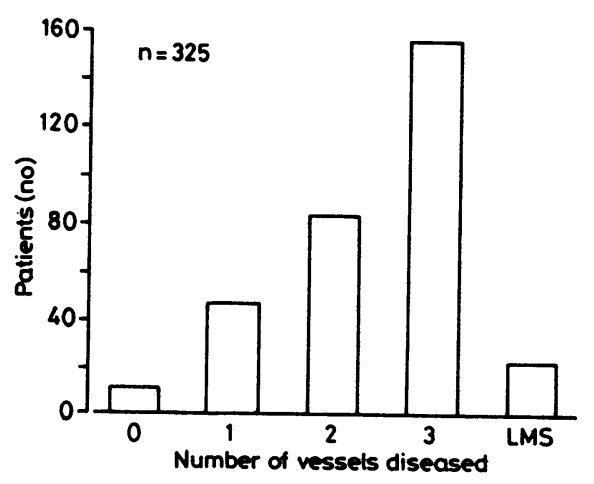

Fig. 2 The distribution of coronary artery disease in the patients investigated 1979-84. The abcissa records the number of vessels affected or left main stem (LMS). European Coronary Surgery Study Group criteria were used. ${ }^{12}$

declined to $70 \%$ in 1984 . The overall 28 day mortality fell from $6 \%$ in 1981 to $3 \%$ in 1983 .

\section{VALVAR HEART DISEASE}

The mean (SEM) age of patients undergoing surgery for valvar heart disease remained constant during the study period at $62(2.5)$ years; the sexes were equally represented. The waiting list times resembled those experienced by patients with ischaemic heart disease. In $57 \%$ of the 119 referrals aortic valve disease was present and $13 \%$ of these had co-existent coronary artery disease that required grafting. All patients in the latter group had angina pectoris. The operative mortality was $5.9 \%$ overall for aortic valve replacement, including those who

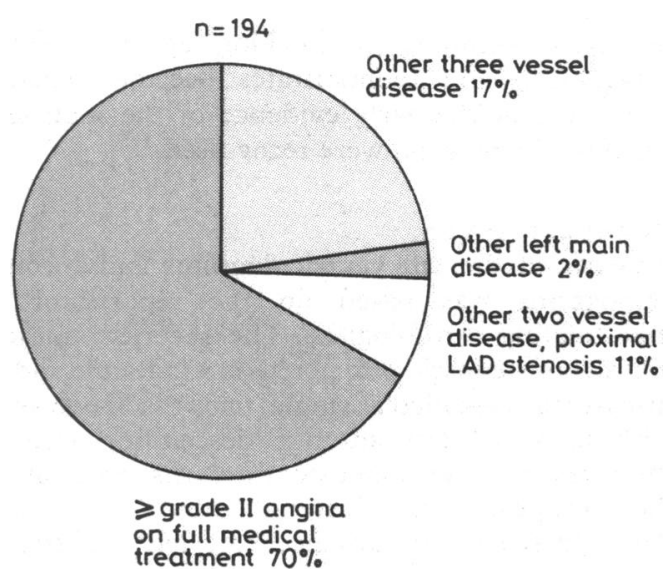

Fig. 3 Distribution of angiographic findings in relation to symptoms and treatment based on 1982-84 figures only (see text). Twelve patients with inoperable coronary artery disease were excluded. LAD, left anterior descending artery. 
Table 1 Miscellaneous procedures classified as "other" (see text)

\begin{tabular}{|c|c|c|c|c|c|c|c|}
\hline Other procedures & 1979 & 1980 & 1981 & 1982 & 1983 & 1984 & Total \\
\hline $\begin{array}{l}\text { Electrophysiological study } \\
\text { "Cardiomyopathy" } \\
\text { Congenital heart disease } \\
\text { Aortic dissection } \\
\text { Pulmonary embolism } \\
\text { Pericardial disease } \\
\text { Primary pulmonary hypertension } \\
\text { Total }\end{array}$ & $\begin{array}{r}5 \\
1 \\
4 \\
1 \\
0 \\
0 \\
0 \\
11\end{array}$ & $\begin{array}{l}1 \\
4 \\
1 \\
1 \\
0 \\
0 \\
0 \\
7\end{array}$ & $\begin{array}{l}2 \\
0 \\
0 \\
1 \\
3 \\
2 \\
0 \\
8\end{array}$ & $\begin{array}{l}0 \\
1 \\
4 \\
2 \\
0 \\
1 \\
0 \\
8\end{array}$ & $\begin{array}{l}3 \\
2 \\
0 \\
0 \\
0 \\
1 \\
0 \\
6\end{array}$ & $\begin{array}{l}2 \\
3 \\
1 \\
0 \\
1 \\
1 \\
1 \\
9\end{array}$ & $\begin{array}{r}13 \\
11 \\
10 \\
5 \\
4 \\
5 \\
1 \\
49\end{array}$ \\
\hline
\end{tabular}

had coronary artery bypass grafts. There was one death after cardiac catheterisation (concealed haemorrhage from an iliac vessel). Two patients died on the waiting list for operation (heart failure, suicide).

\section{PERMANENT PACEMAKER INSERTION AND MISCELLANEOUS PROCEDURES}

Figure 1 shows the number of permanent pacemaker insertions each year. Table 1 gives the referrals for miscellaneous cardiological conditions. The numbers are too small for further analysis.

\section{GENERAL PRACTITIONER SURVEY}

Sixty two practitioners providing primary health care to 124684 patients had not referred patients directly out of the district. One hundred and two coronary artery bypass procedures were performed on patients registered with these general practitioners during 1982-84. This corresponds to 273 operations per million population per annum. The remaining 45 practitioners said that some of their patients had been referred out of the district. The reasons given for direct referral included delay in obtaining outpatient appointments at the district hospital, previous experience of delays at the referral centres used by the district hospital, and referral by employment health schemes. Few of the general prac- titioners had accurate records of the numbers of patients referred or their fate. Estimates ranged from none to 15 operations per annum. Nevertheless 73 of the 95881 patients on the lists of these practitioners came to coronary artery operation through the district cardiac unit, either after emergency admission or because the district facilities had been used on that occasion. This group of practitioners accounted for 254 operations per million population per annum. This figure excludes patients referred directly out of the district.

When the general practitioners were ranked according to the number of patients registered with them who came to operation during the study there was a wide variation. Table 2 gives the apparent need for operation on patients of the "top scoring" $50 \%$ or $25 \%$ of the general practitioners expressed as the number of operations per million population per annum.

\section{NATIONAL HEART AND BROMPTON \\ HOSPITALS SURVEY}

During 1983 eight patients underwent coronary artery bypass grafting at the Brompton and National Heart Hospitals and two underwent valve operation. ${ }^{13}$ Four patients came from outside the catchment area during 1982-84 and underwent coronary artery bypass grafting and during 1984 six came to

Table 2 Calculation ${ }^{\star}$ of the requirement for coronary artery bypass grafting (CABG)

\begin{tabular}{|c|c|c|}
\hline Data & $C A B G$ procedurest & $\begin{array}{l}\text { Valve operations } \ddagger \\
\text { (per million } \\
\text { population per annum) }\end{array}$ \\
\hline $\begin{array}{l}\text { (a) North West Surrey Health District } \\
\text { (b) Corrected for cross boundary flow } \\
\text { (c) Corrected for regional variation in SMR (see text) } \\
\text { (d) Corrected to include only symptomatic (NYHA grade II) patients on } \\
\text { full treatment (see text) } \\
\text { (e) Top } 50 \text { th percentile of GPs (see text) } \\
\text { (f) Top } 25 \text { th percentile of GPs (see text) }\end{array}$ & $\begin{array}{r}327 \\
362 \\
464 \\
\\
325 \\
643 \\
1716\end{array}$ & $\begin{array}{l}79 \\
79 \\
79 \\
- \\
- \\
-\end{array}$ \\
\hline
\end{tabular}


valve operation. Cross boundary flow was thus balanced for valve operation but a small adjustment was needed for coronary artery bypass procedures (see Table 2).

\section{Discussion}

There have been no previous detailed reports of the requirement in the United Kingdom for invasive cardiological investigation and operation nor has the operational experience of a district hospital cardiological unit been similarly reported. Fry in his general practice survey found an incidence of angina of $0.39 \%$ per annum. ${ }^{14}$ The Research Committee of the Northern Regional Faculty of the Royal College of General Practitioners suggested that about $\mathbf{3 0 0}$ patients per million population per annum developed "severe" angina. This was not based on information about treatment or angiographic findings. ${ }^{15}$ The recent consensus statement that the United Kingdom required a provision for 300 coronary artery bypass graft operations per million population per annum was anecdotal. ${ }^{16}$

Our data show a rise and latterly some decline in the number of patients operated upon for ischaemic heart disease while no similar trend has been seen in operation for valvar heart disease. There are several explanations for this. Initially there may have been a backlog of referrals. The publication of the findings of the European Coronary Surgery Study Groups in 1982 suggesting that operation enhanced survival in three vessel and two vessel disease with a proximal left anterior descending coronary artery stenosis, irrespective of symptoms, ${ }^{12}$ influenced decision making. More recently the Coronary Artery Surgery Study has questioned this. ${ }^{17}$ The local requirement expressed as procedures per million population per annum is $\mathbf{3 6 2}$ for ischaemic heart disease (and includes percutaneous transluminal coronary angioplasty and re-operations), 79 for valve operation, 87 for permanent pacemaker insertion, and $\mathbf{4 0}$ for miscellaneous conditions. The figure for coronary artery bypass grafting may be adjusted if it is assumed that the standardised mortality ratio for North East Surrey Health District (0.78) reflects the local prevalence of ischaemic heart disease. If this is the case the national need for coronary artery bypass procedures increases to 464 when the local need is divided by the standardised mortality ratio.

There was much variation in the number of patients referred by general practitioners. Possible explanations include chance, age distribution of patients, and the general practitioner's attitude towards operation. By examining the top 50th and the top 25th percentile of practitioners we estimated the effect if all general practitioners had referred pa- tients at the same rate. These estimates (Table 2) may reflect more closely the true need in the community for coronary artery procedures and are closer to the provision for operation in other countries. The most recently available data suggest a national provision in Australia of $420^{18}$ and in the United States of about 800 coronary procedures per million population per annum. ${ }^{3}$

Indications for coronary artery operation include angina resistant to medical treatment and the possibility of improving survival. The three major randomised trials that have been reported, however, are to some extent contradictory. ${ }^{12} 1719$ Hampton has reviewed them and he concluded that disabling angina may be the only indication for operation. ${ }^{20}$ If so, the current United Kingdom provision (excluding percutaneous transluminal coronary angioplasty) at $171^{21}$ is approximately one half of the 325 operations that our data suggest are required for symptoms alone. If operation is also offered for enhancement of survival in left mainstem stenosis, three vessel disease, and two vessel disease with a proximal left anterior descending artery stenosis 1219 the present national provision is less than a third of that required. To some extent the need for coronary artery operation reflects the policy of the referring centre. Thus in the North West Surrey District all patients in whom coronary artery disease is overt (that is after myocardial infarction) or suspected on the basis of symptoms undergo non-invasive evaluation if they are aged $\leqslant 60$ years. Assessment above this age is more selective.

The North West Surrey District requires 79 operations per million population per annum for valvar heart disease. This compares with the total United Kingdom figure (76) ${ }^{1}$ and that of South Australia (74) ${ }^{22}$ both expressed in the same units. There was a modest growth in the uptake of these procedures between 1979 and 1984 but it seems unlikely this will increase further unless the predicted change in the age structure of the population brings a concomitant increase in the need for aortic valve operation which is the predominant problem.

Finally the figures for permanent pacemaker implantation (87 precedures per million population per annum) compare with the national figures (75) which are among the lowest in the Western World. ${ }^{23}$ We think that this in part represents a conservative approach, notably to sinoatrial disease, at the regional centre.

Recently there has been increasing emphasis on the cost effectiveness of coronary artery procedures both in economic terms and in terms of the enhancement of quality of life. ${ }^{1624}$ It is, however, salutory to recall that nine patients (discounting the suicide) died on the waiting list for investigation or oper- 
ation. This represents $2.3 \%$ of all those subsequently undergoing operation and had regional facilities been adequate these deaths could have been avoidable. Attention has already been drawn to the inadequacy of district cardiological services, ${ }^{25}$ the inadequate provision of regional services, ${ }^{1}$ and the poor use of available resources. ${ }^{26}$

\section{Conclusion}

Our data suggest that at best current provision for coronary artery surgery in the United Kingdom caters for between one third and one half of the number of patients who might benefit from it. A more aggressive pattern of referral from general practitioners could increase this requirement still further. Operation for valvar heart disease is more in line with need, although this may not be true of permanent pacemaker implantation.

\section{References}

1 English TAH, Bailey AR, Dark JF, Williams WG. The UK Cardiac Surgical Register, 1977-82. Br Med $\mathcal{f}$ 1984; 289: 1205-8.

2 Kennedy RH, Kennedy MA, Frye RL, et al. Cardiac catheterisation and cardiac surgical facilities: use, trends and future requirements $N$ Engl I Med 1982; 307: 986-93.

3 Kennedy RH, McGoon DC, Smith HC, Kurland LT. Trends in cardiac surgery [Letter]. $N$ Engl f Med 1985; 312: 119-20.

4 Rodewald G, Potorius MJ. Cardiac surgery in the Federal Republic of Germany during 1981. A report by the German Society for Thoracic and Cardiovascular Surgery. Thorac Cardiovasc Surg 1982; 30: 127-9.

5 National Heart Foundation of Australia. Cardiac surgery 1982. A report by the National Heart Foundation of Australia. (Available from the National Heart Foundation of Australia, PO Box 2, Woden, ACT 2606.)

6 Second report of a Joint Cardiology Committee of the Royal College of Physicians of London and the Royal College of Surgeons of England on combined cardiac centres for investigation and treatment with a note on the requirements of cardiology in hospitals outside such a centre. Br Heart $\mathcal{F}$ 1980; 43: 211-9.

7 Office of Population Censuses and Surveys. Mid 1983, final mid 1981 and final mid 1982 population estimates for local government and health authority areas of England and Wales. London: HMSO, 1984. (OPCS Monitor PP1 84/4.)

8 Office of Population Censuses and Surveys. Mortality statistics (Area). London: HMSO, 1983. (Series DHS No. 10.)
9 Joy M, Huggett I. Cardiology in a District Hospital. $\mathrm{Br}$ Med f 1982; 285: 790-2.

10 Criteria Committee, New York Heart Association. Diseases of the heart and blood vessels. Nomenclature and criteria for diagnosis. 6th ed. Boston: Little, Brown, 1964: 1114.

11 Tobins M, Weir EK, Chester E, et al. "Maximal" drug therapy is not necessarily optimal in chronic angina pectoris. I Am Coll Cardiol 1984; 3: 1051-8.

12 European Coronary Surgery Study Group. Long term results of prospective randomised study of coronary artery by-pass surgery in stable angina pectoris. Lancet 1982; ii: 1173-80.

13 South West Thames Regional Health Authority. Cardiothoracic Services: consultation document. London: SWTRHA, 1985.

14 Fry J. Natural history of angina in a general practice. $\mathcal{f}$ $R$ Coll Gen Pract 1976; 26: 643-6.

15 Research Committee, Northern Regional Faculty, Royal College of General Practitioners. Study of angina in patients aged 30 to 59 in general practice. $\mathrm{Br} \mathrm{Med} \mathcal{F}$ 1982; 285: 1319-21.

16 Consensus Development conference: coronary artery by-pass grafting. $\mathrm{Br} \mathrm{Med}$ f 1984; 289: 1527-9.

17 Coronary Artery Surgery Study (CASS). A randomised trial of coronary artery by-pass surgery. Circulation 1983; 68: 939-50.

18 National Heart Foundation of Australia. Cardiac Surgery 1982. A report by the National Heart Foundation of Australia. Woden, Australia, 1982. (Cited by English TAH, Bailey AR, Dark JF, Williams WG. The UK Cardiac Surgical Register 1977-82. Br Med F 1984; 289: 1205-8.)

19 Takas T, Hultgren HN, Lipton MJ, et al. The VA cooperative randomised study of surgery for coronary arterial occlusive disease. Circulation 1976; 54 (suppl 8): 107-17.

20 Hampton JR. Coronary artery by-pass grafting for the reduction of mortality: an analysis of the trials. $\mathrm{Br} \mathrm{Med}$ f 1984; 289: 1166-70.

21 Society of Thoracic and Cardiovascular Surgeons. United Kingdom Cardiac Surgical Register. London: Society of Thoracic and Cardiovascular Surgeons, 1983.

22 Sutherland H D'A. The metamorphosis of cardiac surgery in Australia. I Thorac Cardiovasc Surg 1980; 80: 808-23.

23 Goldman BS, Personnet V (coordinators). World survey of cardiac pacing. PACE 1979; 2: W1-W 17.

24 Williams A. Economics of coronary artery by-pass grafting. Br Med F 1985; 291: 316-29.

25 Chamberlain D, Bailey L, Emanuel $R$, Oliver $M$ Staffing and facilities in cardiology in England and Wales July 1982. Second biennial survey. Br Heart $\mathcal{f}$ 1983; 50: 597-604.

26 Joy $M$. Who cares about cardiology? $\mathrm{Br} M e d f$ f 1984; 288: 339-40. 